\title{
Diagnostic accuracy of preoperative magnetic resonance imaging in predicting curative resection of rectal cancer: prospective observational study
}

\author{
MERCURY Study Group
}

\begin{abstract}
Objective To assess the accuracy of preoperative staging of rectal cancer with magnetic resonance imaging to predict surgical circumferential resection margins.

Design Prospective observational study of rectal cancers treated by colorectal multidisciplinary teams between January 2002 and October 2003.

Setting 11 colorectal units in four European countries. Participants 408 consecutive patients presenting with all stages of rectal cancer and undergoing magnetic resonance imaging before total mesorectal excision surgery and histopathological assessment of the surgical specimen.

Main outcome measures Accuracy of magnetic resonance imaging in predicting a curative resection based on the histological yardstick of presence or absence of tumour at the margins of the specimen.

Results 354 of the 408 patients had a clear circumferential resection margin $(87 \%, 95 \%$ confidence interval $83 \%$ to $90 \%)$. Specificity for prediction of a clear margin by magnetic resonance imaging was $92 \%(327 / 354,90 \%$ to $95 \%)$. High resolution scans were technically satisfactory in 93\% (379/408). Surgical specimens were histopathologically graded as complete or moderate in $80 \%(328 / 408)$, and the median lymph node harvest was 12 (range 0-49). Magnetic resonance imaging predicted clear margins in 349 patients. At surgery 327 had clear margins (94\%, $91 \%$ to $96 \%)$.

Conclusion High resolution magnetic resonance imaging accurately predicts whether the surgical resection margins will be clear or affected by tumour. This technique can be reproduced accurately in multiple centres to predict curative resection and warns the multidisciplinary team of potential failure of surgery, thus enabling selection of patients for preoperative treatment.
\end{abstract}

\section{Introduction}

Colorectal cancer is a common malignancy and the second commonest cause of cancer death in the Western world. Rectal cancer, defined as a tumour with its lower edge within $15 \mathrm{~cm}$ from the anal verge, accounts for about a third of all colorectal malignancies. Management is particularly challenging technically for the surgeon and local recurrence within the pelvis is a common result of treatment failure. ${ }^{12}$

In total mesorectal excision surgery, the plane of dissection is formed by the mesorectal fascia, which encloses the fatty mesorectum that envelops the rectum. This fascia forms the cir- cumferential resection margin, and tumour within $1 \mathrm{~mm}$ of the potential circumferential resection margin (the radial margins of the surgical resection specimen) strongly predicts local recurrence and poor survival. ${ }^{2}{ }^{3}$ While the optimal surgical technique of total mesorectal excision can cure early stage localised rectal cancer, ${ }^{3}{ }^{4}$ it is now evident that preoperative radiotherapy or chemoradiotherapy ${ }^{5}$ may facilitate successful surgical excision and therefore improve outcome in patients with more extensive disease. Previous studies have found high rates of tumour in the circumferential resection margins; $22-27 \%$ in recent studies. ${ }^{6-8}$ Therefore, the optimal management of rectal cancer requires detailed preoperative planning that includes the assessment of the relation of tumour to the mesorectal fascia. ${ }^{9}$ Traditionally, surgeons have assessed patients with digital rectal examination, ${ }^{10-12}$ endorectal ultrasonography, and occasionally computed tomography. ${ }^{13-15}$ Though these methods confer little knowledge of the relation of tumour to the surgical circumferential resection margin, preoperative treatment strategies have been based on digital rectal assessment of how the tumour is fixed. ${ }^{16}{ }^{17}$ Postoperative treatment is based on the histopathological assessment of the margin. Clearly, patients with potentially affected margins need to be identified preoperatively so that this may be reduced with preoperative therapy ${ }^{18}{ }^{19}$ and, if appropriate, by modifying the planned surgery. The potential complexity of preoperative decision making in the management of rectal cancer lends itself to a multidisciplinary team approach. The team consists of surgeons, radiologists, oncologists, pathologists, and specialist nurses, aided by a broad range of administrative and supportive workers from hospital and community services.

High resolution magnetic resonance imaging consistently shows the mesorectal fascia, and one prospective study found that it could predict tumour at the potential circumferential resection margin if the tumour was within $1 \mathrm{~mm}$ of the mesorectal fascia on the scan. ${ }^{20-22}$ Variable acceptance of the technique is attributable to reports alleging inaccuracy and doubt in some quarters as to its clinical and cost effectiveness. ${ }^{14}$

We undertook a prospective European, multicentre, multidisciplinary study, with emphasis on quality control of imaging assessment, surgery, and pathology, to assess the diagnostic accuracy, feasibility, and reproducibility of magnetic resonance imaging in predicting the final histopathological staging of tumour within $1 \mathrm{~mm}$ of the circumferential resection margin.

A list of the members of the MERCURY Study Group, details of imaging sequences, and a copy of the proforma can be found on bmj.com. 


\section{Methods}

Consecutive patients with rectal adenocarcinoma proved by biopsy from 11 hospitals were eligible for the study. Patients had to be over 18 years of age and able to give written informed consent. Patients were excluded if they were pregnant or had a history of pelvic malignancy, pelvic radiotherapy, or pelvic floor surgery for faecal incontinence or rectal prolapse. Patients were also excluded if they were unable to undergo magnetic resonance imaging because of metal fragments or implanted metal devices within the body. Data were prospectively collected, using detailed proformas.

Clinical assessment of tumour - A specialist colorectal surgeon $(n=30)$ at each centre assessed the tumour with digital rectal examination and rigid sigmoidoscopy. Tumours were classified as mobile, tethered, or fixed. Colonoscopy or contrast enema was used to exclude polyps or synchronous cancer. Mobile tumours were considered to have a potentially clear circumferential resection margin. Tethered or fixed tumours were considered to have a potentially threatened or affected margin.

Radiological assessment-Patients underwent magnetic resonance imaging of the pelvis with a body coil and a high resolution protocol for imaging the primary tumour and mesorectal fascia before surgery (see bmj.com). This was repeated after subsequent treatment in patients who received chemoradiotherapy or long course radiotherapy before surgery. Computed tomography was used to stage metastases. Eighteen radiologists (with 5-20 years' experience in gastrointestinal and magnetic resonance imaging) reported on the scans before surgery and were blinded to the histopathological findings. Imaging workshops were held before the study started to ensure standardisation of scan techniques, image interpretation, and reporting. ${ }^{20123-25}$ All scans were reported with a dedicated proforma (see bmj.com). If the scan showed tumour $\leq 1 \mathrm{~mm}$ from the mesorectal fascia, circumferential resection margins were classified as potentially affected.

Treatment options-The clinical and radiological findings for each patient were discussed at a preoperative multidisciplinary team meeting. For patients identified preoperatively by magnetic resonance imaging as having a potentially affected margin, the team agreed a preoperative treatment strategy to reduce the likelihood. Treatment options included extending the surgical resection to remove structures beyond the mesorectal fascia en bloc, short course $(5 \times 5 \mathrm{~Gy})$ radiotherapy, ${ }^{26}$ long course radiotherapy, or chemoradiotherapy.

Histopathological assessment-This was taken as the reference standard. Sixteen specialist gastrointestinal histopathologists (with 5-25 years' experience) defined a clear margin as $\geq 1 \mathrm{~mm}$ between the tumour and the margin. ${ }^{27}$ Pathology workshops were held before the study to standardise pathological examinations and naked eye and microscopic assessment of specimens.

\section{Statistics}

We wanted to be able to show that using magnetic resonance imaging to aid decisions about preoperative treatment would correctly identify $95 \%$ of patients who had clear margins on surgery, but we also wanted to rule out a lower limit of $90 \%$. We used a Simon single stage design ${ }^{28}$ to rule out a rate of less than $90 \%$ with an estimated true rate of $95 \%$. We calculated the sensitivity, specificity, positive predictive accuracy, and negative predictive accuracy for magnetic resonance imaging and digital rectal examination in predicting a curative resection based on the histological yardstick of presence or absence of tumour at the margins of the specimen.

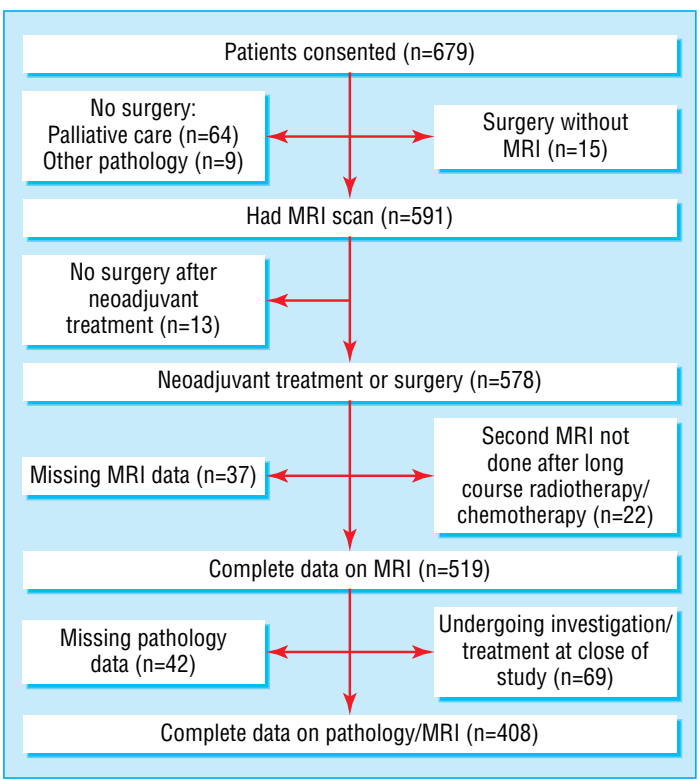

Fig 1 Recruitment of patients and treatment arms (MRI=magnetic resonance imaging)

\section{Results}

\section{Patients' characteristics}

Between January 2002 and October 2003, 679 potentially eligible patients consented to take part in this study. After exclusions, we had complete pathology and magnetic resonance imaging data available for comparison in 408 patients (fig 1).

Table 1 summarises patients' characteristics. The quality of surgery was assessed macroscopically. ${ }^{29}$ Of 408 specimens, 251 $(62 \%)$ were complete, $77(19 \%)$ were moderate, and $23(5 \%)$ were incomplete or perforated. No report on specimen grade was recorded in $57(14 \%)$. The median number of nodes found per specimen was 12 (range 0-49).

\section{Magnetic resonance imaging prediction of circumferential resection margin status}

Of the 349 patients in whom magnetic resonance imaging predicted clear margins and who underwent surgery, 327 had clear margins (94\%, 95\% confidence interval 91\% to 96\%) (table 2). The accuracy for predicting the status of circumferential resection margin by initial imaging or imaging after treatment but before surgery in 408 patients was $88 \%$ (359/408, 85\% to $91 \%)$.

Of the 408 patients, 311 underwent primary surgery. The accuracy for prediction of a clear margin was 91\% (284/311, $88 \%$ to $94 \%)$ with a negative predictive value of $93 \%,(269 / 290$, $90 \%$ to $96 \%$ ) (table 2). This compared with an accuracy of $77 \%$ $(75 / 97,69 \%$ to $86 \%)$ and negative predictive value of $98 \%$ $(58 / 59)$ in 97 patients with complete magnetic resonance imaging and pathology data who had received preoperative chemoradiotherapy or long course radiotherapy.

\section{Patients with a curative resection on histopathology}

In total, $354(87 \%)$ patients had a clear margin on histopathology (table 2). In 327 of these patients, this was correctly predicted with magnetic resonance imaging (see fig 2), giving a specificity of $92 \%(89 \%$ to $95 \%)$.

In $27(8 \%)$ of these patients, however, magnetic resonance imaging incorrectly predicted tumour in the margin. Twenty one received chemoradiotherapy or long course radiotherapy, and appearances of tumour at the margin on their scans after treat- 
Table 1 Characteristics of 408 patients undergoing surgery for colorectal cancer. Figures are number (percentage) of patients unless stated otherwise

\begin{tabular}{|c|c|}
\hline & No $(\%)$ of patients \\
\hline Median (range) age (years) & $68(29-92)$ \\
\hline Men & $247(60)$ \\
\hline Women & $161(40)$ \\
\hline \multicolumn{2}{|l|}{ Height of primary tumour (from anal verge): } \\
\hline $0-5 \mathrm{~cm}$ & $139(34)$ \\
\hline $5.1-10 \mathrm{~cm}$ & $145(36)$ \\
\hline$>10.1 \mathrm{~cm}$ & $101(25)$ \\
\hline Missing & $23(6)$ \\
\hline \multicolumn{2}{|l|}{ Tumour differentiation: } \\
\hline Moderately/well & $351(86)$ \\
\hline Poorly & $40(10)$ \\
\hline Unknown & $17(4)$ \\
\hline \multicolumn{2}{|l|}{ Treatment given: } \\
\hline Primary surgery & $311(76)$ \\
\hline Median (range) days from MRI to primary surgery & $26(1-119)$ \\
\hline Surgery after chemoradiotherapy/long course radiotherapy & $97(24)$ \\
\hline $\begin{array}{l}\text { Median (range) days from MRI to surgery after } \\
\text { chemoradiotherapy/long course radiotherapy }\end{array}$ & $30(1-181)$ \\
\hline \multicolumn{2}{|l|}{ Operation performed: } \\
\hline Anterior resection & $294(72)$ \\
\hline Abdominoperineal excision & $86(21)$ \\
\hline Hartmann's procedure & $23(6)$ \\
\hline Extended resection & $5(1)$ \\
\hline \multicolumn{2}{|l|}{ Tumour stage after primary surgery $(n=311)$ : } \\
\hline pT1 & $34(8)$ \\
\hline pT2 & $72(18)$ \\
\hline pT3 & $182(45)$ \\
\hline pT4 & $23(6)$ \\
\hline \multicolumn{2}{|c|}{$\begin{array}{l}\text { Tumour stage after chemoradiotherapy or long course radiotherapy followed by surgery } \\
(\mathrm{n}=117) \text { : }\end{array}$} \\
\hline урT0 & $7(7)$ \\
\hline ypT1 & $2(2)$ \\
\hline урт2 & $21(22)$ \\
\hline yрT3 & $52(54)$ \\
\hline урт4 & $15(15)$ \\
\hline Median (range) nodes found per specimen & $12(0-49)$ \\
\hline
\end{tabular}

$\mathrm{MRI}=$ magnetic resonance imaging; $\mathrm{pT}=$ =stage assessed by pathological examination and tumour size; ypT=tumour also assessed after neoadjuvant treatment.

ment corresponded to changes related to treatment, but no tumour was detected on histopathological assessment. In the six patients who underwent primary surgery with predicted affected margin on magnetic resonance imaging, en bloc removal of adjacent organs in one patient resulted in a clear circumferential resection margin but tumour had breached the mesorectal fascia as predicted on preoperative scan. One patient treated with palliative intent had clear circumferential resection margin but the specimen was incomplete and the surgeon reported gross disease in the pelvis. In three of the six patients histopathology showed a distance of $>1-2 \mathrm{~mm}$ to the circumferential resection margin, indicating close but not affected margin. In one patient overestimation of disease resulted in a false positive result of affected margin with magnetic resonance imaging.

\section{Patients with a non-curative resection on histopathology}

Histopathology showed affected margin in 54/408 (13\%) patients (table 2). In 32 of these patients, magnetic resonance imaging correctly predicted tumour within $1 \mathrm{~mm}$ of the mesorectal fascia. In 17 patients, despite preoperative chemoradiotherapy or long course radiotherapy, the circumferential resection margin remained affected (fig 3).

The 15 remaining patients underwent primary surgery, despite magnetic resonance imaging predicting involved affected margins, because of comorbidity (five patients), irresect-
Table 2 Prediction of status of circumferential resection margin with magnetic resonance imaging in 408 patients including those undergoing surgery after preoperative chemotherapy or chemoradiotherapy

\begin{tabular}{|c|c|c|c|}
\hline & \multicolumn{3}{|c|}{ Status by histopathology } \\
\hline & Clear & Involved & Total \\
\hline \multicolumn{4}{|l|}{ By margin status } \\
\hline \multicolumn{4}{|l|}{ Clear: } \\
\hline Long course radiotherapy/chemoradiotherapy & 58 & 1 & 59 \\
\hline Short course radiotherapy/surgery alone & 269 & 21 & 290 \\
\hline Total & 327 & 22 & 349 \\
\hline \multicolumn{4}{|l|}{ Involved: } \\
\hline Long course radiotherapy/chemoradiotherapy & 21 & 17 & 38 \\
\hline Short course radiotherapy/surgery alone & 6 & 15 & 21 \\
\hline Total & 27 & 32 & 59 \\
\hline Grand total $^{*}$ & 354 & 54 & 408 \\
\hline \multicolumn{4}{|l|}{ By treatment } \\
\hline \multicolumn{4}{|l|}{ Primary surgery/short course radiotherapył: } \\
\hline Clear & 269 & $21 \dagger$ & 290 \\
\hline Involved & 6 & 15 & 21 \\
\hline Total & 275 & 36 & 311 \\
\hline \multicolumn{4}{|l|}{ After chemoradiotherapy§: } \\
\hline Clear & 58 & 1 & 59 \\
\hline Involved & 21 & 17 & 38 \\
\hline Total & 79 & 18 & 97 \\
\hline
\end{tabular}

${ }^{*}$ Accuracy=359/408 (88\%, 95\% confidence interval $85 \%$ to $\left.91 \%\right)$; sensitivity=32/54 (59\%, $46 \%$ to $72 \%)$; positive predictive value (PPV) $=32 / 59(54 \%, 42 \%$ to $67 \%)$; specificity $=327 / 354$ ( $92 \%, 90 \%$ to $95 \%)$; negative predictive value $(\mathrm{NPV})=327 / 349(94 \%, 91 \%$ to $96 \%)$. †10/21 were intraoperative perforations.

$\ddagger$ Accuracy $=91 \%$ (95\% if intraoperative perforations excluded); sensitivity=42\%; PPV $=71 \%$; specificity $=98 \%$; NPV $=93 \%(96.1 \%$, if intraoperative perforations are excluded $)$. $\S$ Accuracy $=77 \%$; sensitivity $=94 \%$; PPV $=45 \%$; specificity $=73 \%$; NPV $=98 \%$.

able metastatic disease (two), planned extended resection to prevent circumferential resection margin involvement (two), and short course radiotherapy followed by immediate surgery (four). Two patients in whom magnetic resonance imaging predicted affected margins were not discussed at a preoperative multidisciplinary team meeting, and no preventive treatment plan was documented.

In 22 of $54(41 \%)$ patients with affected margin this had not been predicted by magnetic resonance imaging before surgery. In 11 this was because of perforation of the tumour during surgery, which could not have been predicted on magnetic resonance imaging. In seven, the affected margin was not due to direct spread of the tumour but to the presence of nodes containing tumour that had not been detected by the scan lying within $1 \mathrm{~mm}$ of the margin. In one patient, changes on the scan were interpreted as post-radiotherapy fibrosis at the margin, but examination of the specimen showed microscopic tumour cells. In three patients, although the local extent of tumour had been correctly documented compared with pathology, the distance to the mesorectal fascia had been overestimated by the reporting radiologist.

\section{Accuracy of digital rectal examination $v$ magnetic resonance imaging}

Magnetic resonance imaging gave more accurate information than digital rectal examination (table 3). In 245 patients who underwent primary surgery, accuracy for circumferential resection margin status was 171/245 (70\%) with digital rectal examination and 226/245 (92\%) with magnetic resonance imaging in the same group of patients $(\mathrm{P}<0.01)$. In particular when digital rectal examination showed fixed or tethered tumour this corresponded to an involved circumferential resection margin in only $15 \%(10 / 68)$ of patients. 
Table 3 Magnetic resonance imaging (MRI) $v$ digital rectal examination in 245 patients assessed by both methods undergoing primary surgery or short course radiotherapy followed by immediate surgery

\begin{tabular}{lccc} 
& \multicolumn{1}{c}{ Clear } & Involved & Grand total \\
\hline MRI prediction at circumferential resection margin: & & \\
\hline Clear & 215 & 15 & 230 \\
\hline Involved & 4 & 11 & 15 \\
\hline Grand total & 219 & 26 & 245 \\
\hline Digital rectal examination: & & & \\
\hline Mobile & 161 & 16 & 177 \\
\hline Fixed/tethered & 58 & 10 & 68 \\
\hline Grand total† & 219 & 26 & 245 \\
\hline
\end{tabular}

${ }^{*}$ Accuracy=226/245 (92\%); sensitivity=11/26 (42\%), positive predictive value (PPV)=11/15 $(73 \%)$; specificity $=215 / 219(98 \%)$; negative predictive value (NPV)=215/230 $(93 \%)$ †Accuracy=171/245 (70\%); sensitivity=10/26 (38\%); specificity=161/219 (74\%); PPV=10/68 $(15 \%)$; NPV=161/177 $(91 \%)$

\section{Discussion}

Magnetic resonance imaging is an accurate method of predicting the possibility of achieving a surgically clear circumferential resection margin. Accurate visualisation of the tumour and pelvic anatomy has become the focal point in the multidisciplinary team management of rectal cancer. Digital rectal examination has a key role in early diagnosis and is crucial in the hands of an experienced surgeon. ${ }^{10-12}$ We have confirmed, however, that magnetic resonance imaging is the best method available for predicting circumferential resection margin status and therefore clinical outcome.

\section{Importance of radiology and pathology workshops}

We used proformas, based on published national guidelines, ${ }^{30} 31$ to ensure quality control in collecting data. Before launch of the study all radiologists attended intensive training workshops, using comparative materials from magnetic resonance imaging and histopathology. These workshops focused on interpretation of images and acquisition techniques, which require considerable skill and were an important part of the success in achieving consistency and reproducibility in this multicentre trial.

Surgeons used optimal total mesorectal excision surgery, ${ }^{3}{ }_{32}$ and the histopathologist graded only $5 \%$ of 408 specimens as incomplete. This compares favourably with $24 \%$ of 180 specimens in another large study. ${ }^{33}$ Dedicated workshops achieved high quality pathology results, with multiple blocks, whole mount sections, and a median lymph node harvest of 12 to standardise detailed assessment of the specimens. Within the United Kingdom this concept of standardisation and quality control has formed the basis of a national multidisciplinary team development programme for colorectal teams to introduce the concepts of precision staging with magnetic resonance imaging, appropriate use of neo-adjuvant therapy, and planned optimal surgical intervention. ${ }^{34}$ The UK members of the group are currently responsible for radiological training and mentoring in this programme.

\section{Study limitations}

In patients in whom magnetic resonance imaging predicts that clear circumferential resection margins are achievable by the surgeon, $94 \%$ will have a clear margin on histology. On the other hand, identification of affected margins on magnetic resonance imaging provides a clear warning that tumour shrinkage before surgery is the patient's best hope of histologically clear margins and the undeniable implication of better outcome. Magnetic resonance imaging, however, does have some limitations as some patients had affected margin because of lymph nodes containing tumour foci within $1 \mathrm{~mm}$ of the margin and intraoperative perforations not predicted by the scan. Intraoperative perforations (occurring in $<3 \%$ of surgical specimens) reflect technically difficult surgery and further work is required to determine why these occur with investigation of any physical
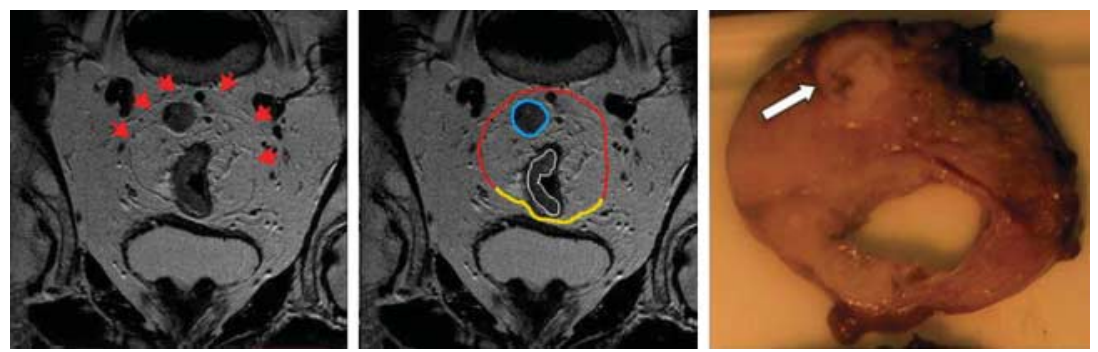

Fig 2 Assessment of circumferential resection margins. Oblique axial thin section magnetic resonance imaging and corresponding gross tissue slice. The scan depicts an intermediate signal intensity (grey) upper third rectal tumour (outlined in white). The mesorectal fascia (red line) is shown as a thin low signal intensity (black) line enveloping the mesorectum posteriorly with the peritoneal reflection anteriorly (yellow line). The scan shows a malignant lymph node (blue line) close to the mesorectal fascia. The potential circumferential margin is defined as clear on the scan because this distance is $2 \mathrm{~mm}$. The tissue slice shows the malignant node (arrow) close to the margin with a distance $>1 \mathrm{~mm}$. The margin is therefore clear
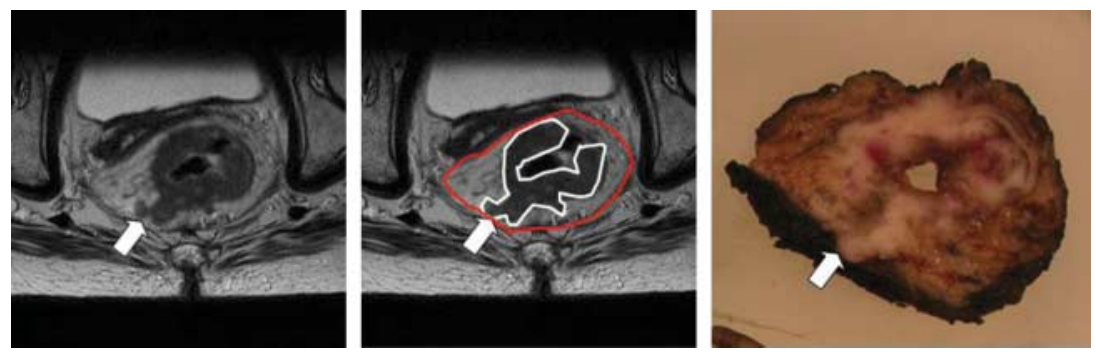

Fig 3 Involved circumferential resection margin predicted by magnetic resonance imaging. Oblique axial thin section imaging and corresponding gross tissue slice. The scan depicts an intermediate signal intensity (grey) mid-third rectal tumour (outlined in white). The mesorectal fascia is shown as a thin low signal intensity dark line enveloping the mesorectum (red line). The scan shows a tongue of tumour lying against the mesorectal fascia (arrow). The potential circumferential margin is defined as affected on the preoperative magnetic resonance imaging because the distance to the mesorectal fascia is $<1 \mathrm{~mm}$. The tissue slice shows tumour affecting the surgical circumferential margin. The margin is therefore affected as predicted by magnetic resonance imaging 
parameters (such as height of tumour, narrow pelvis) seen on magnetic resonance imaging that may predict this. As lymph nodes not identified by magnetic resonance imaging within 1 $\mathrm{mm}$ of the margin contained only small foci of tumour and were encapsulated, it is not clear from previous audits of histopathology if outcomes are poor for this small subgroup of patients. There were also patients in whom magnetic resonance imaging predicted affected margin but who had clear margins on histopathology. This was a reflection of the aggressive steps taken by the multidisciplinary team in preventing positive marginsnamely, by extending surgery and giving preoperative radiotherapy or chemoradiotherapy. Our results show that the degree of tumour regression after preoperative treatment is often underestimated because of inability to distinguish treated tumour from non-viable tumour "scar." By correlating the scan result with histopathology sections in this series we may be able to learn how to improve our interpretation of post-treatment scans. Despite the obvious limitation of inability to distinguish a few residual cancer cells within an area of radiation fibrosis, however, we were able to predict clear circumferential resection margin after radiotherapy with a high degree of accuracy as shown by the low false negative rates. Our overall rate of affected margin of 13\% compares favourably with previous audited results of $27 \%$ and confirms the value of our preoperative multidisciplinary management of rectal cancer.

In summary, we have shown that magnetic resonance imaging of rectal cancer is accurate, feasible, reproducible, and a robust standard for preoperative staging. In conjunction with clinical assessment it allows a multidisciplinary team to plan individualised treatment. The potential benefits include avoidance of unnecessary preoperative treatment in many patients, an objective staging system for future clinical trials, and targeted therapy for those who require it.

\section{What is already known on this topic}

In rectal cancer, the presence or absence of tumour within 1 $\mathrm{mm}$ of the surgical circumferential resection margins (of the excised surgical specimen) strongly influences outcome and is an independent predictor of survival and local recurrence

The presence of tumour at the circumferential resection margin influences whether the patient should receive preoperative treatment

\section{What this study adds}

Magnetic resonance imaging is the best method of assessing the relation of the tumour to the potential circumferential resection margin-the mesorectal fascia

This technique is reproducible in multiple centres with committed multidisciplinary teams

Most patients with potentially affected margins can be identified at presentation, thus preventing incomplete resection of the tumour and local recurrence

Staging with magnetic resonance imaging provides an accurate assessment of tumour spread before preoperative treatment, allowing for standardisation of inclusion into clinical trials
We thank all the radiologists, pathologists, surgeons, and nurse specialists who were members of the MERCURY Study Group and were responsible for conception and design of the study and collection of data (see bmj.com for details). The following hospitals took part in this study: Pelican Cancer Foundation, The Ark, North Hampshire Hospital; Royal Marsden Hospital Colorectal Network, Royal Marsden Hospital; St Helier NHS Trust; Mayday University Hospital; North Hampshire Hospital; Leeds Hospitals Teaching Hospitals, Leeds General Infirmary; St James's University Hospital; Norwegian Radium Hospital; Frimley Park Hospital; Ashford St Peters Hospital; Krankenhaus im Friedrichshain; Llandough Hospital; Karolinska University Institute. The Pelican Cancer Foundation supported the trial throughout.

Contributors: G Brown was responsible for conception and design of the study, collected and interpreted data, drafted the manuscript, and is guarantor. I R Daniels was responsible for the conception and design of the study, collected and interpreted data, coordinated the study and critically edited the manuscript. R J Heald, P Quirke, L Blomqvist, D Sebag-Montefiore, B J Moran, T Holm, and J Strassbourg were responsible for conception and design of the study, collected data, and critically edited the manuscript. A R Norman was responsible for conception and statistical design of the study and carried out the statistical analysis. P D Peppercorn was responsible for conception and design of the study and collection of data. S E Fisher was responsible for collection of data. B Mason was responsible for assistance in drafting the manuscript.

Funding: Wessex Cancer Trust and Siemens Medical, through the Pelican Foundation.

Competing interests: None declared.

Ethical approval: The south east multi-centre research and ethics committee in the UK and local institutional ethics review boards in Oslo, Stockholm, and Berlin approved the study. It was adopted within the United Kingdom National Cancer Research Network Portfolio of Studies.

1 Frykholm G, Pahlman L, Glimelius B. Treatment of local recurrences of rectal carcinoma. Radiother Oncol 1995;34:185-94.

2 Birbeck KF, Macklin CP, Tiffin NJ, Parsons W, Dixon MF, Mapstone NP, et al. Rates of circumferential resection margin involvement vary between surgeons and predict outcomes in rectal cancer surgery. Ann Surg 2002;235:449-57.

3 Wibe A, Moller B, Norstein J, Carlsen E, Wiig JN, Heald RJ, et al. A national strategic change in treatment policy for rectal cancer-implementation of total mesorectal excision as routine treatment in Norway. A national audit. Dis Colon Rectum 2002;45:857-66.

4 Martling AL, Holm T, Rutqvist LE, Moran BJ, Heald RJ, Cedemark B. Effect of a surgical training programme on outcome of rectal cancer in the County of Stockholm. Stockholm Colorectal Cancer Study Group, Basingstoke Bowel Cancer Research Project. Lancet 2000;356:93-6.

5 Sauer R, Becker H, Hohenberger W, Rodel C, Wittekind C, Fietkau R, et al. Preoperative versus postoperative chemoradiotherapy for rectal cancer. $N$ Engl $J$ Med 2004;351:1731-40

6 Wibe A, Rendedal PR, Svensson E, Norstein J, Eide TJ, Myrvold HE, et al. Prognostic significance of the circumferential resection margin following total mesorectal excision for rectal cancer. BrJ Surg 2002;89:327-34.

7 Marr R, Birbeck K, Garvican J, Macklin CP, Tiffin NJ, Parsons WJ, et al. The modern abdominoperineal excision: the next challenge after total mesorectal excision. Ann Surg 2005;242:74-82.

8 Kapiteijn E, Marijnen CA, Nagtegaal ID, Putter H, Steup WH, Wiggers T, et al. Preoperative radiotherapy combined with total mesorectal excision for resectable rectal cancer. $N$ Engl J Med 2001;345:638-46.

9 van Lingen CP, Zeebregts CJ, Gerritsen JJ, Mulder HJ, Mastboom WJ, Klaase JM. Local recurrence of rectal cancer after total mesorectal excision without preoperative radiotherapy. Int J Gastrointest Cancer 2003;34:129-34.

10 Mason AY. Selective surgery for carcinoma of the rectum. Aust $N Z J$ Surg 1976;46:322-9.

11 Nicholls RJ, Galloway DJ, Mason AY, Boyle P. Clinical local staging of rectal cancer. $\mathrm{Br}$ J Surg 1985;72(suppl):S51-2.

12 Nicholls RJ, Mason AY, Morson BC, Dixon AK, Fry IK. The clinical staging of rectal cancer. BrJ Surg 1982;69:404-9.

13 Mackay SG, Pager CK, Joseph D, Stewart PJ, Solomon MJ. Assessment of the accuracy of transrectal ultrasonography in anorectal neoplasia. Br J Surg 2003;90:346-50.

14 Bipat S, Glas AS, Slors FJ, Zwinderman AH, Bossuyt PM, Stoker J. Rectal cancer: local Bipat S, Glas AS, Slors FJ, Zwinderman AH, Bossuyt PM, Stoker J. Rectal cancer: local
staging and assessment of lymph node involvement with endoluminal US, CT, and MR staging and assessment of lymph node involvement with
imaging - a meta-analysis. Radiology 2004;232:773-83.

15 Zerhouni EA, Rutter C, Hamilton SR, Balfe DM, Megibow AJ, Francis IR, et al. CT and MR imaging in the staging of colorectal carcinoma: report of the Radiology Diagnostic Oncology Group II. Radiology 1996;200:443-51.

16 Mohiuddin M, Regine WF, John WJ, Hagihara PF, McGrath PC, Kenady DE, et al Preoperative chemoradiation in fixed distal rectal cancer: dose time factors for pathological complete response. Int J Radiat Oncol Biol Phys 2000;46:883-8.

17 Mohiuddin M, Regine WF, Marks G. Prognostic significance of tumor fixation of rectal carcinoma. Implications for adjunctive radiation therapy. Cancer 1996;78:717-22.

18 Mawdsley S, Glynne-Jones R, Grainger J, Richman P, Makris A, Harrison M, et al. Can histopathologic assessment of circumferential margin after preoperative pelvic histopathologic assessment of circumferential margin after preoperative pelvic
chemoradiotherapy for T3-T4 rectal cancer predict for 3-year disease-free survival? Int J Radiat Oncol Biol Phys 2005;63:745-52.

19 Burton S, Brown G, Daniels IR, Norman AR, Mason B, Cunningham D. MRI directed multidisciplinary team preoperative treatment strategy: the way to eliminate positive circumferential margins? BrJ Cancer 2006;94:351-7. 


\section{Research}

20 Brown G, Radcliffe AG, Newcombe RG, Dallimore NS, Bourne MW, Williams GT Preoperative assessment of prognostic factors in rectal cancer using high-resolution magnetic resonance imaging. BrJ Surg 2003;90:355-64

21 Brown G, Richards CJ, Newcombe RG, Dallimore NS, Radcliffe AG, Carey DP, et al. Rectal carcinoma: thin-section MR imaging for staging in 28 patients. Radiology 1999;211:215-22

22 Blomqvist L, Rubio C, Holm T, Machado M, Hindmarsh T. Rectal adenocarcinoma: assessment of tumour involvement of the lateral resection margin by MRI of resected specimen. Br J Radiol 1999;72:18-23.

23 Brown G, Daniels IR, Richardson C, Revell P, Peppercorn D, Bourne M. Techniques and trouble-shooting in high spatial resolution thin slice MRI for rectal cancer. Br J Radiol 2005;78:245-51.

24 Brown G, Richards CJ, Bourne MW, Newcombe RG, Radcliffe AG, Dallimore NS, et al Morphologic predictors of lymph node status in rectal cancer with use of high-spatialresolution MR imaging with histopathologic comparison. Radiology 2003;227:371-7.

25 Brown G, Kirkham A, Williams GT, Bourne M, Radcliffe AG, Sayman J, et a High-resolution MRI of the anatomy important in total mesorectal excision of the rectum. AJR Am J Roentgenol 2004;182:431-9.

26 Improved survival with preoperative radiotherapy in resectable rectal cancer. Swedish rectal cancer trial. N Engl J Med 1997;336:980-7.

27 Adam IJ, Mohamdee MO, Martin IG, Scott N, Finan PJ, Johnston D, et al. Role of circumferential margin involvement in the local recurrence of rectal cancer. Lancet 1994;344:707-11

28 A'Hern RP. Sample size tables for exact single-stage phase II designs. Stat Med 2001;20:859-66.
29 Maughan NJ, Quirke P. Modern management of colorectal cancer-a pathologist's view. Scand J Surg 2003;92:11-9.

30 Association of Coloproctology of Great Britain and Ireland. Guidelines for the management of colorectal cancer. London: Royal College of Surgeons of England, Association of Coloproctology of Great Britain and Ireland, 1996:65.

31 Williams GT, Quirke P, Roval College of Pathologists Working Group on Cancer Services. Minimum data set for colorectal cancer histopathology reports. London: Royal College of Pathologists, 1998

32 MacFarlane JK, Ryall RD, Heald RJ. Mesorectal excision for rectal cancer. Lancet 1993:341:457-60.

33 Nagtegaal ID, van de Velde CJ, van der Worp E, Kapiteijn E, Quirke P, van Krieken JH. Macroscopic evaluation of rectal cancer resection specimen: clinical significance of the pathologist in quality control.J Clin Oncol 2002;20:1729-34.

34 What is the government doing to improve outcomes for patients with bowel cancer? Colorectal Dis 2004;6:521-4.

(Accepted 2 August 2006)

doi 10.1136/bmj.38937.646400.55

Correspondence to: G Brown, Royal Marsden Hospital, Surrey SM2 5PT gina.brown@rmh.nhs.uk

This is version 2 of the paper. The first version did not credit the Pelican Foundation for its support and funding. 